\title{
EDUCADORAS FEMINISTAS: CONTINÚA LA REVOLUCIÓN INCONCLUSA NICARAGÜENSE ${ }^{1}$
}

\author{
Montserrat Fernández Piñón \\ Docente en Managua, Nicaragua \\ Estudiante de Doctorado en Educación \\ de la Universidad de Costa Rica
}

Recibido 21-XI-2005

Resumen: Este artículo ubica y documenta el desarrollo y los aportes de la educación feminista en Nicaragua en el contexto socio-histórico y político en el que surge y evoluciona, utilizando como referente conceptual y temporal la Revolución Sandinista, a la cual hacen referencia las 67 educadoras feministas entrevistadas para la tesis doctoral que sirve de base a este artículo, "Espiritualidad en la educación: concepciones de educadoras feministas de la Nicaragua de inicios del siglo XXI".

Palabras clave: Educación, feminismo, revolución, cambio social.

\begin{abstract}
This article situates and documents the development and contributions of Feminist Education in Nicaragua in the socio-historical and political context in it emerges and evolves. It takes the Sandinista Revolution as a conceptual and time reference, as discussed by the 67 feminist educators interviewed for the doctoral dissertation "Spirituality in Education: Understandings of Feminist Educators in Nicaragua at the beginning of the XXI Century", which is the basis for this article.
\end{abstract}

Key words: Education, feminism, revolution, social change.

\section{Aceptado 25-IV-2006}

"En 1979, cinco de cada diez nicaragüenses no sabía leer ni escribir. Con la Cruzada Nacional de Alfabetización (CNA) medio millón de habitantes fue alfabetizado (...). Veinticinco años han pasado (...). La épica de aquel movimiento alfabetizador radicó en una juventud que, motivada inicialmente por solidaridad humana o por valores cristianos, abrazó la responsabilidad del cambio social y culminó con éxito y enorme satisfacción esa tarea (...).

Tenemos derecho de volver a creer. A pesar de los conjuros, el mesianismo, el caudillismo y la demagogia, la utopía social no muere porque es la idea fuerza que nos impulsa a movilizarnos y transformar el mundo con la certeza de que éste puede ser mejor. Recuperaremos nuestras propias voces con una ética política que no defraude a la juventud, ni a nuestras madres y padres, ni a nuestros amigos y amigas mártires”.

Proclama Movimiento XXV Aniversario $C N A^{1}$

\section{Introducción}

\section{Motivación personal}

Soy una nicaragüense nacida en Barcelona que llegó a Nicaragua después de la CNA de 1980, en 1988. Varias de mis colegas educadoras feministas (EF) en Nicaragua participaron como brigadistas 
o alfabetizadoras en la CNA. Ellas y yo seguimos creyendo en las utopías y en los procesos revolucionarios, esta vez inmersas en nuestro quehacer en universidades, instituciones estatales o internacionales, colectivos de mujeres u ONGs mix$\operatorname{tas}^{2}$ o como consultoras independientes. Muchas veces, después de 1990, cuando converso con nicaragüenses o personas de otras nacionalidades, me preguntan por qué sigo viviendo en Nicaragua. Desde 1993-4, fecha en que me incorporo al movimiento de mujeres en Nicaragua, suelo contestar: me satisface mi quehacer como educadora popular feminista y me siento orgullosa de compartir con muchas mujeres en lo que encuentro, hoy en día, como el movimiento social más revolucionario en la Nicaragua del siglo XXI: el movimiento de mujeres.

De las 67 EF (autodefinidas como tales) que entrevisté con motivo del estudio doctoral que estoy realizando, titulado hasta el momento "Espiritualidad en la educación: concepciones de educadoras feministas de la Nicaragua de inicios del siglo XXI", y que sirve de base a este artículo, 31 identificaron explícitamente la revolución como una influencia espiritual en sus vidas. Así lo define una de ellas: "En los años 80 la fuerza de la revolución sandinista, ... la forma en que me impliqué en todo ese proceso y lo viví, pues, intensamente... Ésa fue una fuerza espiritual única que influyó, que ha influido mi vida" (EF53:14).

Con el presente artículo, pretendo ubicar y documentar el desarrollo y los aportes de la educación feminista en Nicaragua en el contexto socio-histórico y político en el que surge y evoluciona, utilizando como referente conceptual y temporal la Revolución Sandinista, a la cual hacen referencia las EF entrevistadas. Creo, al igual que Mary Nash, que "la redefinición del movimiento de las mujeres en clave de reconocimiento, respeto y mutua centralidad es uno de los retos abiertos para las mujeres del siglo
XXI” (Nash, 2004:298). Y agregaría que para cualquier sociedad que se precie de democrática.

\section{Organización y estructura del contenido}

Este artículo incluye un acápite de contexto sociopolítico para, posteriormente, hacer un recorrido por la educación en Nicaragua en las últimas cuatro décadas y el papel de las EF durante ese período. Sostengo que la educación nicaragüense, durante la dictadura somocista, crece en respuesta al auge de la Alianza para el Progreso (ALPRO) promovida en toda la región. La educación feminista, y en particular la educación popular feminista (EPF), durante los años 80, durante la "Revolución", está subordinada al proyecto revolucionario nacional, período en el que las feministas empiezan a encontrar en los líderes masculinos sandinistas las mismas prácticas patriarcales que en los somocistas. En los años 90 en adelante, con el cambio de sistema, el movimiento feminista, muy lejos de hundirse, se fortalece: su discurso es de crítica abierta, sin dualidades, y resurgen las posturas liberadoras, sobretodo canalizadas por las educadoras feministas, frente a las recetas del BID y el Banco Mundial (BM), dominantes en el panorama educativo.

El artículo, en un primer acápite, presenta un breve contexto en el que ubicar a las EF en Nicaragua. El segundo aborda las definiciones de los conceptos de revolución y educación feminista. Un tercero desarrolla el recorrido por las cuatro décadas de la educación en Nicaragua expresadas en las experiencias de las EF y su contexto socioeducativo y feminista, apartado que pretende solamente describir algunos aspectos característicos de las distintas generaciones de EF, sin hacer análisis comparativos. Y el cuarto proporciona las consideraciones finales. 


\section{Contexto sociopolítico}

Nicaragua, república independiente desde 1821, con constitución que la declara como tal desde 1838, es una de las naciones centroamericanas que ha sufrido con mayor crudeza la intervención británica y estadounidense. En 1932 el general Augusto César Sandino resistió la ocupación norteamericana, pero fue traicionado por el comandante de la Guardia Nacional, Anastasio Somoza García, quien lo mandó asesinar en 1934, aprovechando un encuentro pactado con el fin de firmar un armisticio. A partir de ese momento, el clan Somoza gobernó dictatorialmente acumulando riquezas y poder bajo protección estadounidense.

En materia de educación superior, durante las décadas del 60 y del 70, el movimiento estudiantil universitario participó de las luchas populares en cada uno de los países centroamericanos y al mismo tiempo promovió la integración regional (Levenberg, 1995). Algunas de las participantes del estudio también fueron protagonistas de esas luchas.

\subsection{Datos sociodemográficos}

Actualmente, Nicaragua tiene una población estimada de 5,3 millones (INEC/ CELADE, 2003). Según el VII Censo de Población y III de Vivienda, del 1995, último existente (INEC 1997, Agosto), la población total era 4357099 , de la cual 2147106 son mujeres. La población femenina se repartía en 1242225 urbana y 967768 rural.

Según el mismo censo (INEC 1997), de las 1862315 mujeres de 5 años y más, 1815770 (97,5\%) tienen como lengua materna el español, 31665 (1,7\%) el miskitu, $10892(0,58 \%)$ el inglés, 3,079 $(0,17 \%)$ el sumo/mayagna, y $909(0,05 \%)$ otra. De las 67 EF entrevistadas, ninguna es miskita ni mayagna. La ausencia de estos grupos poblacionales puede deberse a las limitaciones del estudio (la convocatoria abierta fue realizada por medios que no están al alcance de las comunidades miskitas y mayagnas de la Costa Caribe nicaragüense: correo electrónico, teléfono y contacto directo con la investigadora) o al hecho de que en estas comunidades étnicas o lingüísticas no hay mujeres que se identifiquen como educadoras feministas, ya sea que la identidad feminista no sea parte de su vocabulario, ya sea que no forme parte de sus historias personales.

\subsection{Datos socioeducativos}

En Nicaragua, las mujeres muestran las siguientes estadísticas de nivel educativo: $15 \%$ sin acceso a ningún nivel educativo, 43,4\% algún nivel de primaria, $26,6 \%$ algún nivel de secundaria, 5,7\% algún nivel universitario, 3,3\% educación técnica (INEC/CELADE 2003).

Según el Censo de Docentes del 2002 realizado por Emilio Porta y Roberto Gutiérrez para el Ministerio de Educación, Cultura y Deportes (MECD), el total de docentes (no tiene información segregada por sexo) en el año 2002 es de 43972. De éstos, el 35,6\% son empíricos (15 667) y el $64,4 \%$ (28 305) posee algún título docente. Cabe señalar que dentro de la categoría empírico se considera a docentes que poseen título universitario pero que no está relacionado a la docencia (Porta y Gutiérrez, 2003). En cuanto a las EF entrevistadas, una tiene algún nivel de primaria, dos algún nivel de secundaria, una es bachiller que ha ejercido de educadora por décadas, diez tienen universidad inacabada (por estar estudiando todavía algunas y otras que dejaron sus estudios universitarios durante la Revolución), siete tienen diplomados en educación y enfermería o carreras técnicas (administración y secretariado ejecutivo), 22 son licenciadas, seis licenciadas con maestrías iniciadas, 14 con maestrías acabadas, tres licenciadas con doctorados iniciados y una doctora en 
educación. Teniendo en cuenta las estadísticas de nivel educativo de mujeres en Nicaragua, mencionadas anteriormente, las EF en general tienen un nivel educativo muy superior a la media nacional de las mujeres y superior a la media nacional del magisterio.

$\mathrm{Su}$ formación universitaria es en las disciplinas de derecho, psicología, educación, trabajo social, sociología, periodismo, economía, teología, ingeniería agronómica, antropología, ecología, farmacia, español y bibliotecología. Con formación universitaria de distinto nivel en educación hay 14 educadoras, o sea, una de cada cinco. En ese sentido, la formación en docencia es menor que la del magisterio nacional.

\subsection{Ciudadanía de las mujeres}

Seis problemas persisten en América Latina en la actualidad en detrimento de la ciudadanía de las mujeres (Molyneux, 2003/2001) y con los cuales se confrontan las EF:

a) La falta de una cultura política y un programa sostenido que alimente y promueva el espíritu democrático e igualitario de las reivindicaciones feministas, informe a la ciudadanía acerca de sus derechos y la anime a perseguirlos.

b) La consiguiente falta de atención a la necesidad de democratizar las instituciones del estado y el partido, volviéndolas internamente más democráticas, "favorables a las mujeres", transparentes y sujetas a la rendición de cuentas ante sus electorados.

c) La falta de una masa crítica de mujeres en posiciones de autoridad que pueda apoyar la realización de estos cambios.

d) Una resistencia generalizada, tanto burocrática como personal, a integrar plenamente a las mujeres en los ámbitos del poder público como "sujetos de las políticas públicas”. e) La tendencia de algunos gobiernos a imponer su propia agenda a las unidades femeninas de formulación de políticas.

f) El riesgo de que dichas unidades pierdan el contacto con el movimiento en conjunto.

\section{Definiciones y conceptos}

\subsection{Concepto de revolución}

Según Helio Gallardo (1992), podemos considerar dos formas de entender el término revolución: una lo reduce a la práctica de la toma (y ejercicio) del poder (propuesta por diversas tendencias políticas) y la otra se concentra y expresa las prácticas plurales y complejas que configuran la capacidad histórico-social de los actores y fuerzas sociales para ejercer un nuevo tipo de poder, o sea, una categoría del discurso moderno.

Como categoría del pensar, la revolución es significativa sólo en relación con otros conceptos y categorías. Debe asociarse, en sentido estricto, primero, con liberación y emancipación. Liberación y emancipación, a su vez, hacen referencia a procesos de autodeterminación de sujetos. "Liberarse" consiste en ir ganando la condición de sujeto, cada vez, e histórica y socialmente. Pueden haber actores sociales, identidades psicológicas, instituciones y estructuras y situaciones sociales (técnicamente hablando, actores, instituciones y estructuras de dominación) en articulaciones diversas que nieguen específicamente la condición de sujeto a los seres humanos y a los diversos sectores sociales. Socialmente, lo revolucionario consiste en la configuración de sujetos colectivos cuya actuación o testimonio de denuncia y transformación radical pone de relieve los diversos aspectos injustos o deteriorados o inviables de un sistema de dominación (Gallardo, 1992). El testimonio de denuncia del sistema patriarcal que hacen las 
feministas las convierte en sujetas revolucionarias, hoy en día y desde siglos atrás.

\subsection{Concepto de educación feminista}

\subsubsection{Conceptos de educación y feminismo}

De las mil y una definiciones de educación que existen ${ }^{3}$, y relacionada con el concepto de revolución, consideraremos la perspectiva de la educación como instrumento de emancipación y liberación personal y de transformaciones sociales. Concretamente, hablamos de la educación crítica, que "es sinónimo de educación para la transformación de los ciudadanos, que son "formados" como "talentos humanos", pensadores autónomos capaces de imaginar y de crear más allá de su conocimiento previo, con el derecho a tener derechos y con la responsabilidad de seres socio-históricos" (De Souza, 2003:6).

El pensamiento feminista y la expresión más contemporánea del feminismo como movimiento social constituyen un fenómeno histórico complejo, con múltiples corrientes. No existe un único canon universal del feminismo. Sin entrar a discutir sobre todas las corrientes teóricas del feminismo (feminismo liberal, radical, posmoderno, postestructuralista, postcolonialista, ecofeminista, de la diferencia, de la igualdad, de la igualdad en la diferencia, lesbiano, anti pornográfico, multicultural, dialógico, etc. $)^{4}$, cabe mencionar que, en América Latina y América Central, la expresión feminista tuvo una gran expansión desde principios del siglo XX, teniendo en Nicaragua a doña Josefa Toledo de Aguerri (1940) como un ejemplo dentro del mundo de las educadoras feministas. En ese momento, el término englobaba de forma plural, distintas expresiones de resistencia y de lucha por los derechos de las mujeres.

Abogamos, igual que Nash (2004), por una interpretación histórica en plural de los feminismos caracterizada por sus múltiples manifestaciones, por lo que se emplean definiciones diversas. Como categoría de análisis histórico, el feminismo es "un proceso abierto, en constante reelaboración en función del contexto político y de los avances historiográficos, de la teoría feminista y de los estudios de las mujeres" (Nash, 2004:66). Los entornos políticos, sociales, culturales y académicos y el desarrollo de la teoría feminista y de la historiografía han influido sobre los modos de interpretar el feminismo. En Nicaragua, las influencias han sido muchas y variadas.

\subsubsection{Educación femenina y feminista}

La educación femenina siempre ha tenido un carácter diferenciado de la masculina, además de plantearse de forma discriminatoria para el género femenino (Aubert et al., 2004). Hemos pasado de la educación separada de niñas y niños a la educación mixta, y de ésta a la coeducación, aunque en muchos casos, sobre todo en Nicaragua, todavía nos hallamos en la educación mixta. En la transmisión de los conocimientos y los saberes, habitualmente no se incluyen las aportaciones femeninas a la ciencia y a la cultura.

En cuanto a la educación feminista, cabe señalar que su teorización es todavía muy incipiente y escasa. En Nicaragua ha tenido mayor impulso y expansión desde las mujeres y grupos feministas fuera de la academia que desde ésta. A pesar de ello, poco escribimos acerca de nuestras prácticas en los grupos de mujeres porque predomina una cultura oral. Al mismo tiempo, desde la academia, los programas de investigación en América Latina han tenido como ámbito el sistema educativo reglado en sus distintos niveles (educación preescolar, primaria, secundaria, técnica y universitaria) y han invisibilizado los procesos educativos que se dan fuera de la escuela, en especial, los que realizan decenas de grupos de mujeres en comunidades remotas del país y del continente. 
Al igual que Gore (1996), creemos que la importancia de identificar espacios para la ruptura del régimen de la pedagogía estriba en el intento de comprender las prácticas pedagógicas en ámbitos no institucionalizados o institucionalizados de forma diferente. Gore señala la universidad y la escuela como las dos instituciones que parecen más importantes en la integración de las relaciones de poder de la pedagogía feminista (Gore, 1996). Nos atreveríamos a decir, por las razones mencionadas en el párrafo anterior, que los grupos feministas, al menos en América Latina, son otra institución, poco estudiada. El ámbito extraescolar en el que se mueven la mayoría de estos grupos permite mayor rapidez en los cambios para responder a la realidad social circundante. La educación feminista ha desempeñado un papel en los movimientos sociales $\mathrm{y}$, por ende, en las transformaciones sociales, y no sólo en la reproducción social, como en el caso del proceso revolucionario nicaragüense. En particular, ha fortalecido los movimientos de mujeres que, a su vez, repercuten en el entramado de los movimientos sociales que apuntan hacia una verdadera democracia en su dimensión sustantiva, más allá de los aspectos formales y fundamentales (Vinent, 2001). Por esta razón resulta importante conocer mejor a las EF de este ámbito.

Desde los 70, América Latina se caracteriza por la proliferación de organismos, programas y experiencias de educación no formal para mujeres y por la falta de sistematización, evaluación y difusión de los mismos (Fernández, 2002). Los estudios sobre los 70 y 80 (Valdés, 1998; Moser, 1993; Ruiz, 1994, 1995; De Puelles y Torreblanca, 1995; Ballara, 1995; Zúñiga, 1995, 1996; Van Dam, 1995; Meentzen, 1993, citados en Messina, 2001) distinguen dos modalidades: educación popular (EP) con mujeres y capacitación feminista. La primera se orienta a la promoción de las mujeres en sectores populares y la otra constituye una búsqueda de opciones de educación para mujeres. El proceso de divorcio entre la EP y el feminismo -que privó en la década de los 80 - parece haberse superado con iniciativas de educación popular feminista (EPF) que incorporan la perspectiva de género en sus planteamientos en los noventa (D'Angelo, 1999; Cane, 2000; Kane, 2001; Nadeau, 2002), superación de la vieja dicotomía entre educación popular con mujeres y capacitación feminista (Pedersen, 1988; Bonder, 1994; Araya, 2001; Messina, 2001). La clave, desde una visión retrospectiva (Vinent, 2001), es el no fomentar dicotomías ni oposiciones entre las diferentes problemáticas de dominación, distinto que en los 80 durante la revolución nicaragüense.

Las memorias de actividades educativas de los centros de EPF constituyen parte de la investigación sobre las mismas (memorias de talleres de Cantera, CISAS, Grupo Venancia y Comité de Mujeres Rurales de León, en Nicaragua, y publicaciones de Las Dignas y CIAZO en El Salvador, entre otras). El aporte más significativo de la EPF es incorporar al análisis de opresión propio de la EP la doble discriminación que sufren las mujeres de sectores populares, por razones de clase y de género. Esta doble dimensión mantiene en el horizonte la transformación del sistema capitalista y del sistema patriarcal y además pretende la eliminación de la dualidad clase-género que no es más que la expresión de formas complementarias de dominación (Vinent, 2001). Los aportes de la EPF incluyen una concreción aún mayor del interés emancipador al especificar, dentro de los oprimidos, el colectivo de mujeres, tomando en cuenta que debe ser incorporada al análisis detectando las contradicciones que se dan en el ámbito privado, los aspectos subjetivos, el saber cotidiano de las mujeres y el fortalecimiento de la organización y consolidación del movimiento de mujeres en vistas a la construcción de una sociedad sin dominación alguna (Vinent, 2001). La EPF aporta un proyecto que elimina toda subordinación: 
machismo, clasismo, racismo y, en definitiva, todo tipo de dominación (Rosero, 1987, en Vinent, 2001).

Fernández y Loría (1988:247, en Vinent, 2001) califican estas innovaciones desde las mujeres en la EP como "gérmenes de una nueva revolución” y comentan:

... existen gérmenes de una nueva revolución que está surgiendo en sus vidas y que las está marcando y transformando de tal manera que asistimos a la modificación de las expectativas sociales en cuanto al rol que deben desempeñar las mujeres... Las mujeres de los sectores populares llevan a los movimientos sociales nuevos aspectos que están revolucionando prácticas y discursos con un planteamiento que integra los afectos, lo subjetivo, lo económico, lo social y lo político...

\subsubsection{Quiénes son educadoras feministas}

$\mathrm{Al}$ inicio del estudio en el que se fundamenta este artículo, había un problema metodológico: cómo saber quién era EF en Nicaragua ya que no existen registros. No sabíamos cuáles eran los puntos de partida con los que contábamos en el mundo de la educación feminista en Nicaragua. Este estudio es una primera aproximación a ese mundo.

Por un lado, supusimos que ciertas educadoras tendrían reservas para identificarse como tales por toda la estigmatización social que se promueve del feminismo desde instituciones y organizaciones sociales conservadoras (medios de comunicación, iglesias, instituciones estatales, escuelas...). Algunas feministas dicen que otras no son feministas, haciendo uso de una práctica que llamamos el "feministómetro". Por otro lado, pensamos que muchas de las $\mathrm{EF}$, al igual que las educadoras en general en Nicaragua, tienen conocimientos empíricos en cuanto a educación se refiere. $\mathrm{O}$ sea, no han recibido formación académica en el campo educativo. Algunas tienen otro tipo de formación profesional (abogadas, psicólogas...) y otras carecen de formación académica superior.
Es por eso que en esta investigación de caracterización de las EF en Nicaragua, definimos a la educadora feminista como toda mujer, proveniente de cualquier profesión o actividad laboral, que realiza acciones formativas en las que promueve propuestas de superación de las desigualdades sociales entre mujeres y hombres ${ }^{5}$.

\section{Educadoras feministas: cuatro décadas de educación en Nicaragua}

\subsection{Durante la dictadura somocista (1960-1980)}

A partir de 1961, Estados Unidos lanzó en América Latina la estrategia de la "Alianza para el Progreso" (ALPRO), para contrarrestar los efectos de la revolución cubana. Aunque la iniciativa fracasó, puesto que los países no sólo no "progresaron" sino que se empobrecieron y se endeudaron en mayor grado, tuvo algunos efectos que posteriormente serían canalizados en forma positiva a favor de los sectores populares, como la aparición del "Desarrollo Comunitario" como método de trabajo popular, el cual, a pesar de su aplicación manipuladora y desmovilizadora, incorporó conceptos como "participación" y "necesidad sentida" que luego se redefinirían emancipatoriamente (Nuñez, 1989:35-36).

Marco Raúl Mejía (Vinent, 2001), educador colombiano del Centro de Investigacióny Educación Popular(CINEP), resalta cómo la revolución cubana (1959), además del lanzamiento de la ALPRO, desencadenó en todo el subcontinente americano una serie de iniciativas organizadas desde la izquierda política, cuya principal consigna era impulsar una revolución de inspiración marxista que erradicara las desigualdades de clase y que naciera de los propios procesos latinoamericanos en los cuales el motor de la transformación social sería no la vanguardia obrera sino más 
bien la coalición entre distintas fuerzas sociales que, con el tiempo, irían consolidando el término de lo popular. El énfasis de estas acciones educativas, en el marco de la izquierda, consistió en promover organización revolucionaria que protagonizaría procesos de transformación social. Para ello, privilegiaron los análisis de la realidad socio-política del momento, la teoría marxista y la elaboración de estrategias alternativas de cambio.

Sin embargo, estas iniciativas también tenían dinámicas de contradicción interna. Hacia adentro de estas iniciativas, prevalecía un vacío de formación política para sus militantes, razón por la cual crearon procesos de educación popular (Mejía, 1992, en Vinent, 2001), movimiento formado a partir de los aportes de Paulo Freire y su Educación Liberadora. Este movimiento se extendió rápidamente por el continente, al ser aplicado con éxito a una multitud de experiencias emancipadoras en localidades campesinas, sindicatos, movimientos estudiantiles, barrios, organizaciones populares y comunidades eclesiales (Nuñez, 1989:3536). En el campo de la educación de personas adultas se promovieron programas de alfabetización o de capacitación técnica y se acompañaron procesos de reforma agraria; $\mathrm{y}$ en las ciencias sociales se incorporaron métodos de investigación social llevados por los mismos sujetos populares. La clave de estos procesos educativos consistía en partir de la propia realidad de las personas participantes para luego, en una reflexión colectiva, plantear estrategias de cambio y transformación de la misma, siguiendo una lógica de acción-reflexión-acción.

Muchas mujeres participaron de estas iniciativas revolucionarias y de educación popular. Una de las EF entrevistadas relata:

los años 67,68 al $70 \ldots$ nazco vinculada primero a un movimiento de barrio ... asistía a un grupo que se llamaba Guardia Juvenil Cristiana. Esa fue mi primerita experiencia, la que... me permitió vincularme con los barrios de Miralagos y el Open tres... era la toma de conciencia con la realidad, con un mundo de injusticia que no estaba tan claro en Nicaragua... Antes de entrar a la Universidad ya nosotros habíamos empezado con un trabajo educativo bien bonito... todas nosotros nos metimos en una cuestión en esa época ya subversiva, era ir a los barrios, hacer análisis de la realidad porque hacíamos encuestas. Pero tal vez ésa no fue la práctica educativa más fuerte. La práctica educativa más fuerte fue cuando el Instituto Juan XXIII empezó a desarrollar acciones con estudiantes de irnos a vivir a las comunidades rurales. Para mí ésa fue mi primera práctica de Sociología. ...estudiábamos la situación de la comunidad, impartíamos charlas, hacíamos trabajo de educación con Alfalit. Y la influencia más grande que tuvimos ahí como educadoras fue con Manolo Morales... allí fueron mis primeros cursos como educadora. A partir de eso... empezamos... a visitar lugares y nos íbamos a vivir 2, 3 meses hasta 6 meses, yo no me acuerdo cómo hacía yo para desaparecerme... eran unas experiencias lindas. Nos fuimos a San José de Cusmapa (EF26:8, 14).

Ellas ya engrosaban los frentes de lucha como sindicalistas, estudiantes, campesinas $y$, aunque en menor grado, como combatientes de frentes armados. Algunas, aunque pocas, tuvieron puestos de dirección como dirigentes sindicales o estudiantiles, o incluso como comandantes guerrilleras.

\subsubsection{Catolicismo social y mujeres}

En el plano eclesial fue muy trascendente la renovación de la Iglesia Católica con el Concilio Vaticano II (1962-1965), que la abrió al mundo actual y a una pastoral creativa y comprometida con la realidad, legitimando una serie de prácticas pastorales innovadoras que ya habían comenzado en América Latina: vida comunitaria al estilo de las primeras comunidades cristianas, lectura y análisis de los "signos de los tiempos" $"$ actuales (modernidad, injusticia social, etc.), compromiso y servicio concreto con los pobres, a destacar. Estas prácticas y experiencias dieron paso en el plano teórico a la Teología de la Liberación $(T L)^{7}$, que inspiró a amplios sectores de la iglesia a comprometerse con el pueblo para luchar por su desarrollo y su liberación (Nuñez, 1986:36). Muchos sacerdotes, religiosas y 
seglares se lanzaron a experiencias de "inserción en la realidad de los pobres" en comunidades campesinas, indígenas 0 en barrios marginales, conociendo así, de primera mano sus condiciones de vida y su problemática social con el método del verjuzgar-actuar. Algunas EF entrevistadas formaron parte de ello, como vimos antes.

En 1979, durante la III Conferencia de Obispos Latinoamericanos reunidos en Puebla, México, se retomó nuevamente la línea profética seguida en Medellín, insistiendo en la "opción preferencial por los pobres y oprimidos" y se especificó más la diversidad de sus rostros: los indígenas, los obreros, las mujeres. ${ }^{8}$ Estos hechos ejercieron gran influencia en el surgimiento de la EPF al obligar la búsqueda de alternativas educativas que incorporaran la presencia y participación real de mujeres de sectores populares.

En el campo eclesial, experiencias como las de las Comunidades Eclesiales de Base (CEB), el movimiento de Delegados o Celebradores de la Palabra ${ }^{9}$, la Pastoral de la Tierra y la Pastoral de Derechos Humanos, son algunas de las prácticas innovadoras que se dieron en toda la región. Para estos movimientos se desarrollaron innumerables procesos de capacitación y formación pastoral -siguiendo la metodología de la EP-dirigidos a campesinos o pobladores pobres, jóvenes y adultos, hombres y mujeres, sectores caracterizados por un alto grado de analfabetismo, pobreza y marginación. Los contenidos de dichos procesos incluían el análisis de la realidad social, económica y política del momento; la confrontación de la misma mediante una lectura bíblico-eclesiológica desde la perspectiva de la Teología de la Liberación y el planteamiento de acciones transformadoras (Mejía, 1992:30, en Vinent, 2001).

La participación de las mujeres en estas actividades y movimientos eclesiales liberadores fue -y sigue siendo- numerosa. Muchas ejercieron liderazgo como agentes de pastoral en calidad de catequistas, coordinadoras de pastoral juvenil, animadoras de Comunidades Eclesiales de Base o Delegadas de la Palabra, como algunas de las EF entrevistadas:

Después o antes del terremoto, todos estamos ya consolidando el movimiento cristiano... nuestro trabajo consistía en la alfabetización, en la educación de adultos, toda la educación era un eje. Cuando te digo educación no me refiero sólo a dar clase, sino la cuestión del teatro, una cuestión cultural: hacíamos grupos creativos, ahí surgió un teatro lindo donde andábamos con Carlos Mejía tocando Cristo de Palacagüina... Yo no sé por qué hay un momento en que nos metemos todos en el CEPA... El CEPA se convirtió en un espacio medio camuflado que la iglesia permitió y los Jesuitas llegaron a parar ahí y era todo nuestro trabajo en el Arenal, en las Sabanitas, allá en Nueva Segovia. Fue cuando se formó todo lo de los delegados de la palabra. Todo el equipo que formó el CEPA y que luego formó la ATC. El primer delegado de la palabra que detectamos en Diriamba fue Edgardo García, que después... fue el de la ATC. El trabajo que se hacía, todo era de educación de adultos... todas éramos educadoras... todas estas muchachas que fueron la base del futuro Movimiento Cristiano e incluso pues que todas se metieron al Frente... Quiénes dominaban los espacios. Fíjate que yo creo que nosotras como mujeres teníamos bastante autonomía ... teníamos grandes vínculos con El Salvador donde también se estaba dando este proceso. Incluso nosotros a la ATC le pusimos ATC por la UTC, porque todo nos lo copiábamos (EF26:20, 22).

El 23 de diciembre de 1972 un terremoto destruyó la capital, Managua, dejando 6.000 muertos y enormes pérdidas materiales. El gobierno de Anastasio Somoza Debayle ("Tachito") fue acusado de desviar para beneficio propio fondos provenientes de la ayuda internacional. A partir de ese momento, comenzó a cobrar fuerza el Frente Sandinista de Liberación Nacional (FSLN), fundado en 1962. La guerrilla nucleó a los sectores de izquierda y el empresario y periodista Pedro Joaquín Chamorro, director del diario La Prensa, se convirtió en referente de los sectores empresarios y fuerzas moderadas que se oponían al gobierno. El 10 de enero de 1978 fue asesinado, hecho que desató una protesta popular que terminaría con la dictadura. 


\subsubsection{Contexto feminista}

En Nicaragua, al igual que en el resto de Latinoamérica, dos rasgos caracterizan a los movimientos de mujeres (Molyneux, 2003/2001): el carácter social del feminismo en la región -podríamos llamarlo "feminismo social”-, y su énfasis en la política participativa (segunda ola del feminismo latinoamericano).

Tres son sus fuentes: el socialismo, el populismo y el catolicismo social (Molyneux, 2003). A partir de los años 50, los movimientos feministas y de mujeres en América Latina se inspiran en las ideas de activismo comunitario, empoderamiento y participación surgidas dentro del catolicismo social y la izquierda. Aunque había y hay tensiones entre los movimientos populares de mujeres (integrados por mujeres de bajos ingresos, de clase trabajadora y media) y las activistas feministas (en su mayoría de clase media, con estudios universitarios y orígenes políticos que se remontan a los movimientos estudiantiles de finales de los años 70 y a las organizaciones de izquierda), es indudable que hubo cierto grado de interacción entre ambas corrientes. En Nicaragua, la Revolución acentuó dicha interacción.

Las EF se inscriben dentro de las corrientes que existen en los movimientos de mujeres. En el caso de las nicaragüenses, ha habido influencias de feministas mexicanas que, a su vez, fueron influidas por los argumentos sobre la diferencia más que las de otros países latinoamericanos (Molyneux, 2003/2001).

\subsubsection{Textos y contextos de las educadoras feministas durante la dictadura somocista}

...yo me inicio trabajando... dentro de las organizaciones desde 1974, a través de toda ... la lucha que había en ese momento contra la dictadura. Habían diferentes formas de organizarnos... Aunque yo no conocía a nadie que me pudiera orientar, sí me atraía la lucha por toda la injusticia que vivíamos en el país y principalmente porque yo ya tenía hijos que estaban estudiando. Yo creo que el mismo temor por lo que estaba pasando con los jóvenes, me impulsó a entregarme... Fui metiéndome buscando los espacios donde poder integrarme para poder alcanzar mi objetivo. Y me integré a la lucha de tomas de tierras que era... un mecanismo para desestabilizar la dictadura somocista... Me ... las ingeniaba porque trabajaba en una empresa, y entonces me las ingeniaba en estar momentos ahí, en irme al trabajo, en quedarme a dormir ahí para estar con la gente... decían: pero ¿para qué quiere ésta tierra si usted no vive en el área rural? porque yo vivía en el área urbana... no era la tierra lo que a mí me estaba llamando, me llamaba en ese momento la forma de dónde organizarme y cómo hacerlo... Los campesinos me eligieron para participar en un grupo que salíamos a recaudar fondos para mantener a la gente que estaba en la tierra. Me tocaba ir a los mercados, ir a los colegios, pidiendo comida, pidiendo dinero para poder llevar a esa gente... Como yo venía a los colegios y andaba ahí buscando dinero, entonces ahí me captó AMPRONAC. Comencé a participar en las marchas de las panas vacías... Y una vez, me tocaba hablar en la plaza del Calvario con las mujeres. Y yo venía con un montón de mujeres de Ranchería, pero hubo tanto atraso que cuando llegué, la marcha ya había terminado. Y no pude tener la oportunidad porque era mi primer debut que iba a tener en público, en hablar. Ahí fuimos una vez a una marcha al Teresiano en Managua... cuando ya fue el triunfo de la revolución. Y aún con todo eso así, yo no pude evitar que mis hijos se integraran a los grupos estudiantiles y se juntaran en los grupos de lucha guerrillera... Estaban muy pequeños... no pude evitarlo. Mi casa fue casa de entrenamiento, buzón de armas y una gran ilusión que había en ese momento que era la revolución, verdad, que era la lucha guerrillera. Había una gran esperanza en los cambios, pues tal vez no todo es pérdida, verdad, porque uno de los cambios es el hecho de que podamos hablar, de que la gente conozcamos nuestros derechos, de que la gente no tengamos miedo, hayamos perdido el miedo, porque antes teníamos mucho miedo en la época de la dictadura. Si andabas hablando de luchas guerrilleras, de participación, era a escondidas (EF42:6).

Durante la dictadura nacieron todas las $67 \mathrm{EF}$ entrevistadas, cuyas edades oscilan entre 28 y 67 años de edad ${ }^{10}$. Once de las entrevistadas llevan 32 o más años de práctica educativa. Y otras diez inician su práctica educativa entre el 73 y 79, los años finales de la dictadura. En total, 21 inician su ejercicio de educadoras durante la dictadura, aunque sólo dos de las entrevistadas identifican el inicio de su práctica como educadoras feministas en estos años. 
Estas 21 EF mencionan como fuentes teóricas educativas principalmente la EP (que, en la actualidad, en algunos casos, la relacionan con el constructivismo) unida a otros autores (Gramsci, Foucault, Bowles) y corrientes ideológicas (marxismo, leninismo) que predominaban en el contexto sociopolítico de ese momento histórico, como indicamos.

\subsection{Durante la Revolución (años 80)}

Luego del triunfo de la Revolución, asumió el gobierno una Junta de Reconstrucción Nacional cuyo nombre dejaba en claro cuál era la misión asumida. Además de la falta de recursos, las nuevas autoridades se encontraron con una dura realidad: más de 30.000 muertos, el aparato productivo semidestruido y la mayor parte de las tierras y otros bienes en manos de unas pocas familias lideradas por los Somoza. Las propiedades de los Somoza y sus socios fueron expropiadas con el fin de liquidar la fuente de poder de la dictadura y con el objeto de dotar al Estado de una base para la reconstrucción del país (Levenberg, 1995).

Como toda revolución, la nicaragüense representa una ruptura con el orden establecido que, en este caso, contó con la lucha por la igualdad y los derechos de la mujer como uno de los elementos de diferenciación frente al anacrónico y conservador orden somocista. La equidad de género, la liberación de las mujeres y la erradicación de la discriminación sexual se convirtieron también en una parte fundamental del proyecto revolucionario. Incluso la revolución sandinista es considerada "la primera fuerza política de signo progresista en el continente latinoamericano, que no sólo no condena el feminismo de forma explícita, sino que incorpora la emancipación de la mujer entre sus principios" (Fernández, 2000, en Santamaría, 2002:83).
Superando los niveles comunes de participación femenina dentro y fuera del país, aproximadamente un $30 \%$ de las combatientes, en la lucha contra Somoza fueron mujeres, además de un 60\% que contribuyó como "brigadistas" dentro de las cruzadas de educación que realizó el Frente una vez en el poder (Santamaría, 2002:103-104).

No es extraño, entonces, que muchas mujeres identificaran la Revolución como un hito en sus vidas, como una de las entrevistadas que dice: "La Revolución a mí me marcó mucho en mi forma de ser, en mi forma de sentir y en mi forma de pensar" (EF29:6).

Con una población en edad escolar atendida sólo en un 5,3\% del total y de ella sólo el $0,5 \%$ en el sector público, con índices de analfabetismo superiores al 50\% y una enseñanza de baja calidad, el sandinismo se encontró en 1979 ante un desafío colosal. Los dos grandes objetivos planteados por el gobierno fueron la reconstrucción de edificios, mobiliarios y equipos y la implantación y desarrollo de un nuevo sistema educativo. El 21 de agosto de 1979, simultáneamente con la reapertura del ciclo escolar, el gobierno dio a conocer el Estatuto sobre Derechos y Garantías de los Nicaragüenses, que establecía (artículo 40) que toda persona tiene derecho a la educación y la gratuidad, obligatoriedad y accesibilidad a todas las personas a la enseñanza primaria y secundaria. También consideraba que la enseñanza superior debía hacerse igualmente accesible a todos, sobre la base de la capacidad de cada quien y que la alfabetización era de interés social y responsabilidad de todos los nicaragüenses (Levenberg, 1995:151-152).

Aunque la visión educativa del sandinismo estaba teñida de un reproductivismo más o menos tradicional, el gobierno revolucionario estuvo lejos de cualquier ortodoxia y, por el contrario, recurrió a todas las herramientas posibles y necesarias para garantizar una educación para toda la población, entre ellas la escuela privada. Lo más destacado de la política educativa del gobierno sandinista fue la 
Cruzada Nacional de Alfabetización (CNA). Se le asignó carácter prioritario, tuvo una estructura novedosa y sus resultados fueron espectaculares.

Cerca de 180.000 mujeres y hombres brigadistas, voluntarios, entre ellas varias de las entrevistadas, trabajaron para enseñar a más de 600.000 nicaragüenses, con un costo de 200 millones de dólares que surgieron fundamentalmente de la solidaridad internacional. Como resultado de semejante movilización social, la tasa de analfabetismo bajó al 12 por ciento y se instaló una estructura para la post-alfabetización. Además la campaña rindió otros frutos, verificados a través de la Consulta Nacional (CN) de 1981: el contacto entre miles de jóvenes estudiantes con el trabajo, la vida y las costumbres de la población autóctona y las condiciones de vida de los sectores más marginados de la sociedad (Levenberg, 1995:152-153).

Con la CNA se consolida la Educación Popular. Hubo una participación masiva y "protagónica" de muchas mujeres en la CNA. Leamos algunos ejemplos con sus propias voces:

Otra influencia... espiritual, fue la revolución, pues a mis quince años yo me integré a un proyecto social que fue la alfabetización... (EF38A:37).

... tenía como dieciséis años y pico, mi papá no me quería dejar ir a alfabetizar y un día antes, una tarde antes de que partiéramos me dijo: andate. A esa hora yo tuve que ir al Elvis Díaz a llenar papeles, no habían, entonces me tuve que ir al Ministerio de Educación y al final me fui. Y quedé sólo con mujeres, quedamos con muchachas y como mujeres nos ganamos un espacio ahí entre los campesinos. A pesar de que éramos mujeres... nos respetaban y... en la casa donde yo vivía, vivían nueve hombres, de catorce a cuarenta años, incluyendo mi papá adoptivo, y ellos tenían conmigo una relación, no sé si porque miraban que era una muchacha de la ciudad, sí con respeto, me querían mucho, me cuidaban... De pronto, yo sentía que a pesar de que estaba lejos... yo... como chavala, podía hacer cosas y no tener conflictos... con los chavalos. (EF29:6).

La Cruzada me sirvió muchísimo... me sirvió a nivel increíble porque ahí conocí la EP, luego adaptarla al tema de salud en ámbitos donde había mucho miedo a entrarle. Sobretodo el trabajo con los pacientes de tuberculosis, había mucho miedo... Había que romper las resistencias para poder trabajar con ellos y lograr cambiar de actitud... Había muy poca bibliografía sobre el tema... era casi cuestión de ensayo y error. Entonces, te salía bien aquí, hacele por ahí, te salía mal esto, buscá alternativas, y así, aprendiendo de esa manera. Luego, en el 87 que se dio la posibilidad de fundar el Centro de Mujeres que prácticamente era el primer centro alternativo que surgía en el país después de Matagalpa... Habían compañeras... venezolanas, italianas, que habían trabajado en el tema de la EP con contenido feminista y con ellas, o sea, empezamos a trabajar sobre todo en el tema del maltrato y del aborto... En todo esto, apareció Estela... Estela trabajaba en CIDHAL y venía de vez en cuando a Nicaragua a hacer algunas capacitaciones, a compartir experiencias con gente... en el 88 vino Estela, nos trajo el manual de metodología participativa feminista que elaboró CIDHAL y eso ha sido como la Biblia... apareció luego la obra..."Sobre nuestro cuerpo y nuestra sexualidad" que casi... que es una reliquia... te plantea todo el proceso metodológico... Es un proceso que no se termina de aprender. (EF51:52).

Durante esa misma época, las mujeres de los sectores populares tuvieron presencia significativa como participantes o monitoras de los procesos de alfabetización, promotoras comunitarias o investigadoras, educadoras o participantes. No obstante, la problemática específica de opresión y discriminación que viven las mujeres de sectores marginales y que atraviesa todas las esferas de la vida cotidiana -personal, familiar y social-, en muy raras ocasiones era incorporada en los análisis de la realidad de la mayoría de las experiencias "emancipadoras" de esa época. Las mujeres sólo fueron consideradas en tanto parte del pueblo oprimido y no en tanto mujeres.

De igual manera, en rigor, el gobierno sandinista heredó la ausencia de conocimientos sobre los antecedentes de los grupos étnicos de la Costa Atlántica. Uno de los grupos étnicos en los que el sandinismo encontró una fuerte oposición fue precisamente la comunidad indígena miskita, donde los esfuerzos de integración fracasaron, entre otros, por la utilización de cuadros organizativos provenientes del Pacífico, de características marcadamente distintas. 
Con el cambio de gobierno en Estados Unidos, comenzó en la década del 80 una nueva guerra civil en Nicaragua, esta vez entre las autoridades nacionales y los guerrilleros organizados y financiados por el Pentágono, los "contras", reclutados principalmente entre ex miembros de la Guardia Nacional, a los que se fueron sumando grupos de mercenarios y sectores marginales atraídos por las cuantiosas sumas destinadas por la Casa Blanca para derrocar al sandinismo.

Con ese contexto sociopolítico, si bien las feministas, y en particular las EF, empiezan a encontrar en los líderes masculinos sandinistas las mismas prácticas machistas que en los somocistas, se subordinan al proyecto revolucionario nacional, ya que en esa época se presentaban como antagónicas la lucha de clases y la de género $\mathrm{y}$, ante el problema de la guerra "contra", se apelaba a presentar un frente unido.

... Como dice Pablo Richard es un análisis muy correcto que ya la idea de la toma del poder homogenizada, bajo una vanguardia... se ha modificado, pero que hay propuestas de tomas de poder desde el local, desde diferentes expresiones para hacer una propuesta más de sociedad civil... Muchas mujeres muy buenas han estado en procesos más claros desde el compromiso político... ésa es la manera en que te puedo responder a esa época, el paradigma daba para eso en esa época. Entonces tampoco hay que sentirse culpable... ahora estamos en un paradigma que supera este modelo, que cuestiona una serie de cosas... hay propuestas más claras, más radicales... creo que eso me ayudó a decir... no hay que sentirse avergonzado de que uno haya hecho acciones claras (EF28:96).

... en la década del 80 , no recuerdo si fue en el $85 \ldots$ no recuerdo muy bien una confusión en el movimiento de mujeres... una propuesta, pero esperábamos que la aprobara el dirigente y si no la aprobaba el dirigente nos sentíamos como mal... Una vez yo no recuerdo cuál era exactamente la propuesta y que se llevó a un aniversario... y ahí llegó el dirigente Daniel y entonces el grupo de mujeres hicimos la propuesta y él la relegó y la aplastó... creo que todo el mundo salió cuestionando y yo creo que no volvimos ya... una mayoría comenzó a disentir y a ver que el poder masculino no daba lugar. Pero también nos cuestionábamos nosotros mismos que estábamos esperando la bendición. A veces las contradicciones son buenas porque ayudan a ver, son buenas siempre. (EF24:24).

Con las mujeres empecé en el 80, 79, 80... una vez... el Frente dio una orientación de no hacerle mucho caso a unas argentinas que nos dieron un curso de planificación porque eran feministas. Y como en esa época, planteaban digamos la independencia del movimiento femenino de los partidos políticos, eso era una herejía enorme... Yo me acuerdo cuando desde AMNLAE... decíamos que había que plantear la legalización del aborto... y era un pleito serio porque nos decían que era contrarrevolucionario en ese momento meterse a eso porque entonces, de repente, vos decías: está la guerra, la invasión de los gringos... Entonces, cómo vas comprendiendo que esa vinculación partido-movimiento de mujeres es fregada. (EF36:77).

Yo sé que estoy en pleno proceso y que tengo grandes vacíos todavía... Un poco cliché, pero fue con la revolución, porque fue la revolución la que empezó un trabajo consciente con las mujeres, así lo viví yo... Que tenía que ver con la toma de conciencia de que las mujeres no tienen igualdad de oportunidades en este país. Yo no lo había tomado en cuenta antes. O sea, yo pensaba que era normal... los patrones... A mí no me afectaba. Desde ahí, el comprender a las mujeres, que las mujeres asuman su rol por debajo de los hombres, o incluso por debajo de otras mujeres, no, porque si eso fue lo que te enseñaron, eso es tu normalidad, eso es tu comprensión de la realidad... mi comprensión de mi realidad como mujer en proceso diferente era primero con los discursos feministas. Ve, eso me hace sentido, eso me llega. Y no estuve ligada directamente en la revolución con AMNLAE, pero sí estuve trabajando con la Juventud Sandinista, donde tampoco... se hacía un trabajo para que las mujeres reconociéramos nuestra identidad y donde tampoco los dirigentes... nos daban un trato equiparado... Pero el hecho de ya ser una dirigente, te daba mayores oportunidades que no serlo... mi proceso de toma de conciencia de mi feminidad, ha sido también en ese camino. Y ha sido sobretodo desde mis crisis relacionales de pareja (EF35:15).

\subsubsection{Mujeres de todas partes}

La Revolución hizo que muchas mujeres, provenientes de todos los rincones del mundo (diez de las entrevistadas nacieron fuera de Nicaragua: 5 en Europa, 2 en el Caribe, 2 en México y 1 en EEUU) coincidieran en Nicaragua. Así nos lo cuenta una de ellas: "Los 80 fueron un período de mucha convergencia de pensamientos 
progresistas aquí en Nicaragua y que tuve la posibilidad de acceder, de tener acceso a esos espacios de debate feministas". (EF3:83).

Además, el movimiento de mujeres en Nicaragua no se circunscribe a Managua, la capital (donde nacieron 15 de las 67 entrevistadas y viven 41 de las mismas): 41 de las EF entrevistadas nacieron en los departamentos (18 en municipios de Occidente, 9 en municipios del Sur, 6 en municipios de las Segovias, 4 en municipios del Caribe, 3 en municipios de BoacoChontales y 2 en Matagalpa) y 26 viven en ellos en la actualidad.

De las 67 entrevistadas, 21 iniciaron su práctica educativa entre julio de 1979 y 1989. Dentro de este grupo, las referencias teóricas son más diversas: EP (4) y autores ligados a ella (Freire 6, Felipe Ulloa 1, Cantera 1), propuesta popular participativa (1), EP feminista (1), TL (2), constructivismo (4) y autores relacionados (Vygotski, César Coll - 1), psicólogos transpersonales (Fromm, Jung - 1), formalistas rusos (1), autores de matemática y economía (1), feministas latinoamericanas como Marcela Lagarde (3), CIDHAL de México (1), Gioconda Batres (1) de Costa Rica y las estrategias de empoderamiento (1).

Quince EF manifiestan iniciar su práctica educativa feminista en los 80 . Aquí, un ejemplo:

Yo siento que empecé como educadora en 1988, cuando entré a la Secretaría de la Mujer de la ATC. Allí estuve como 6 meses apoyando labor organizativa, pero cuando vieron que no era mi fuerte y fueron viendo que la cuestión metodológica a ellos se les aportaba... me pasaron al programa de capacitación... que no existía. Digamos que yo lo monté... junto con la Alba y la Olguita Espinoza. Ahí, junto con ellas aprendí... uno, que la labor educativa en sí no era ningún fin, que era un medio importante; que la metodología que utilizaba era fundamental, una buena elección para no repetir lo que hacía el resto del sindicato, porque en el sindicato había el área de capacitación... formación política le decían. Y en la Secretaría no se quiso montar formación política porque el concepto era como... repetir los discursos, una formación muy bancaria pero muy ideologizada, partidaria... estudiar los discursos de Daniel, de Jaime Weelock, de los líderes...
Yo lo que aprendí con estas mujeres es, uno, que tenemos que articular la información con la reflexión feminista y amarrarlo con la organización, o sea, la acción colectiva... los temas ejes los planteábamos... que nos diera para esos tres: la información para empoderarlas más o no empoderarlas... información que les fuera útil para su labor de líder... y su labor frente a los empleadores; la reflexión feminista y la cuestión de acción colectiva para que el trabajo que hicieran fuera pensado para ellas y para las mujeres... una pata de gallina... tres pilares de lo que considerábamos los ejes, elementos fundamentales de la estrategia de formación.

... teníamos ciertos debates con otra gente que nos decía pero por qué no se meten más a la cuestión puramente feminista y que el sindicato haga la labor... de formación organizativa... decíamos... uno, ya sabemos lo que hace el sindicato. Además tenía unos criterios de selección de la gente a formarse que era los líderes... hombres, ahí las mujeres no entraban. Y el sistema de formación que teníamos nosotras era... contactar a mujeres que tuviesen el deseo de participación organizada, y tuviesen deseo de progresar ellas como personas y ofrecerles espacios de formación. Y esas mujeres después fueron ocupando cargos... con un enfoque que pensábamos iba en beneficio de los derechos de la mujer y tenían una serie de armas y herramientas que muchas veces el sistema mixto del sindicato no se las daba... Creo que en la ATC había como un objetivo bien clarito con el área de formación... y bien casado con el tendido organizativo de la Secretaría de la Mujer... por eso no nos metíamos a lo ideológico, qué sé yo, derechos reproductivos, mientras los otros iban a ver convenios colectivos, no nos interesaba porque aquellos iban a hacerlo de una manera que no permitía a las mujeres sacar provecho y además que si nos miraban que nosotras estábamos en otra onda tampoco íbamos a ganar más espacios, porque si las mujeres íbamos a andar con el discurso del orgasmo, del placer, de métodos anticonceptivos y los hombres iban a andar con el discurso de los derechos de los trabajadores, la marcha del 1 de Mayo, y nosotras con la marcha del 8 de Marzo... optamos por una doble militancia, digamos... La otra cosa que nos decían... ya fuera del sindicato, digamos las feministas, por qué ustedes no se dedican a la cuestión sindical feminista y dejan que otras organizaciones entren para que hagan la formación más ideológica feminista o por qué, como no éramos tan lumbreras, verdad, pero nosotras decíamos no, porque hay ya experiencias donde la Secretaría de la Mujer de los sindicatos han dejado que ONGs o grupos externos hagan la formación digamos más feminista entre comillas y luego lo que hay es una separación. En Guatemala... conocí a una organización... donde el esposo, el secretario general, se dedicó a abrir el 
grupo de mujeres. Y entonces la señora, de buena intención, se metió con grupos, con ONGs y grupos feministas y al final se separaron, porque si eran tan machos los compañeros, no podía haber convivencia. (EF3:10-16).

La referencia principal para estas EF es Marcela Lagarde (8), junto a otras autoras latinoamericanas (2) como Martha Lamas (1), Evangelina García Prince (1), Rosario Castellanos (1), Ivone Gebara (1), las Flora Tristán de Perú (1), las chilenas de La Morada (1); las de "la onda de la EP feminista" como Itziar Lozano (1), Norma Vásquez (1), Estela Bello y las mexicanas de CIDHAL - Cuernavaca y CIDHAL - México (1); compañeras de Centroamérica del espacio La Corriente, entre otras, autoras costarricenses (1) como Las Panchas (1), salvadoreñas (1) como Las Dignas (1) y panameñas (2). También venezolanas (1), autoras y grupos nicas como Cantera (1), el Colectivo de Mujeres de Matagalpa (1) y Alan Bolt (1), y autoras europeas como Simone de Beauvoir (2), Celia Amorós (2), Amelia Valcárcel (1), Dolores Juliano (1), Clara Murguialday (1), las feministas de la diferencia italianas de la Librería de Milán (1) como Luisa Muraro (1) y la francesa Luce Irigaray (1), así como otras feministas que trabajan la conciencia corporal como Pina González (1) y Rossanna Rabezzanna (1), y Lidia Wespi (1) que trabaja la parte mágica de los cuentos.

Muchas de las referencias lo son por contacto directo, personal, porque han estado en Nicaragua en una o más ocasiones o han sido citadas en actividades de formación feminista.

El gobierno sandinista convocó a elecciones en 1984 -boicoteadas por la oposición- y fue elegido presidente Daniel Ortega Saavedra. La nueva Constitución fue promulgada el 20 de noviembre de 1986 y Ortega conservó el cargo hasta comienzos de 1990, año en que fue derrotado por Violeta Barrios, viuda de Chamorro, en elecciones costosamente negociadas por la comunidad internacional.

\subsection{Años 90 y siglo XXI}

Los gobiernos de Violeta Barrios de Chamorro, Arnoldo Alemán y Enrique Bolaños conforman la época de las políticas neoliberales, si bien éstas iniciaron en el campo económico a finales de los 80, durante el gobierno revolucionario. Para la región centroamericana, la tendencia que marca la década del 90 parece ser la de la integración económica y la pacificación comenzada en los 80 , elementos que entran en tensión con el intervencionismo extranjero y la continuidad de una hegemonía norteamericana que se ha hecho sentir en esta porción de territorio a lo largo de más de un siglo.

\subsubsection{Contexto socioeducativo latinoamericano y nicaragüense ${ }^{11}$}

En la introducción de 1993 a la Historia de la Educación Iberoamericana compilada por Adriana Puiggrós y Claudio Lozano (1995), la autora y el autor nos plantean las necesidades de dicha historia: mayor desarrollo de estudios locales y regionales; monografías diversas sobre la historia del currículo, del magisterio, de los procesos de alfabetización; la educación fuera de los muros de la escuela; la historia reciente, académicamente descalificada o ignorada en los centros de capacitación pedagógica; la historia de la educación silenciosa y la historia educativa de las mujeres, entre otras tantas necesidades de un largo inventario.

Desde el punto de vista social y educativo encontramos dos bloques diferenciados en América Central: por un lado, Costa Rica y Panamá, y por otro, Guatemala, Nicaragua, El Salvador y Honduras, países que presentan verdaderos abismos socioeducativos entre el ámbito rural y el urbano, entre población indígena y de origen europeo, entre clases dominantes de carácter latifundista y mayorías marginadas, con índices de alfabetización y de 
escolarización que se ubican entre los más bajos del mundo.

Para Honduras, Nicaragua, Guatemala y El Salvador, la más importante de las tareas educativas sigue siendo la integración de las masas campesinas marginadas de la educación, no sólo respetando sus lenguas y sus costumbres sino incorporando además ese discurso popular. El respeto a la diferencia, la aceptación de la palabra del otro como instrumento válido, parecen ser temas a tener en cuenta para cualquier proyecto de cambio educativo en la región.

\subsubsection{Las educadoras feministas en Nicaragua durante los años 90 y el siglo XXI}

La segunda ola (del feminismo) en Nicaragua sentó las bases de un movimiento de mujeres activo y numeroso que dio los primeros pasos hacia la autonomía. La revolución abrió esta posibilidad, pero las mujeres del movimiento serán las protagonistas del cambio y las que demandarán que se dé una revolución dentro de esta revolución: una revolución feminista (Santamaría, 2002:112).

Durante los años 90 y el inicio del siglo XXI, inician su práctica educativa 22 de las EF entrevistadas. Ellas también mencionan diversas fuentes teóricas educativas: la EP (4), Freire (3), Felipe Ulloa (1), la EP feminista (2), las Venancia (1), el libro de CIDHAL (1), el paradigma constructivista (3), Vygotski (1), la Pedagogía de Comenius (1), Marcela Lagarde (3), Gioconda Batres (1), Puntos de Encuentro (1), Chilo Marenco (1) y diferentes corrientes psicológicas como el análisis transaccional (1) y la Psicología conductual, emocional emotiva (1), y corrientes económicas (CELADE e investigaciones y encuestas).

De las $67 \mathrm{EF}$ entrevistadas, inician su práctica educativa feminista en este período 48 de ellas. Marcela Lagarde sigue siendo la autora más referida (15) en este grupo. Diecinueve de estas 48 EF empiezan su práctica educativa feminista después de
1997. Curiosamente, de estas 19 educadoras recién incorporadas a una práctica educativa feminista, 7 llevan entre 20 y 44 años de experiencia educativa, y otras 5 entre 10 y 15 años.

... mi práctica feminista es mucho más reciente... hace 15 años con el movimiento cuando entró fuerte después de la pérdida de la Revolución... entonces me di cuenta... las desventajas de ser mujer cuando quedé desempleada, cuando me sacaron del trabajo, a las primeras que me sacaron fue a las mujeres y se abrió en ese momento una puerta, la apertura de todos estos movimientos que tomaron fuerza a partir del 90 y ya me integré, pues, me acerqué con muchísimo interés y así me fui integrando mucho más y mi práctica yo siento que se inicia directamente con mi trabajo en el campo académico (EF61:10).

En este grupo, hay mayor peso de las referencias cercanas, nicaragüenses. La formación teórica feminista es más escasa, como expresa una de las entrevistadas:

Tampoco tengo una formación teórica feminista amplia, más una práctica feminista la que yo tengo... yo participé en el Movimiento Cristiano Revolucionario, con el FER, con el Frente y hasta llegar a la Revolución. Sin embargo, las marcas de formación teóricas es como mujer más especial no por la parte de la educación feminista, no tuve nada más, todos los aspectos del marxismo, leninismo, pero la parte de educación feminista no la desarrollé. Hasta ahora más bien estoy empezando en este campo. Entonces se puede decir que no lo manejo, verdad, técnicas o alguna formación teórica. (EF32:56).

\subsubsection{Contenidos abordados actualmente}

Siento que yo he tenido una fase de mi vida muy ligada a la política, movimiento revolucionario y todo eso, donde el aspecto social ha sido preponderante, aunque yo en mi infancia, en mi adolescencia, he sido muy mística... Siempre me ha guiado un sentimiento ético de la justicia... Creo que me he metido en el movimiento revolucionario guiada por este sentimiento, estoy segura de eso, porque además, así ha sido en la historia, en la concreta. Pero siento que, en algún momento, lo social estaba aplastando lo íntimo (EF42:8).

Aspectos como los malos tratos y las relaciones afectivo-destructivas a varios niveles, en todas las clases sociales y en 
cualquier edad, se convierten en algunas de las preocupaciones feministas y educativas actuales.

Una buena parte de la práctica educativa realizada por las EF podría considerarse de sensibilización/concientización de género/feminista y formación feminista a diferentes grupos poblacionales: la propia familia y las amistades, el funcionariado estatal del sector salud y judicial, maestras y maestros, personas de organismos (ONGs, agencias...), mujeres y hombres a nivel comunitario tanto rural como urbano, adolescentes, jóvenes, niñez y grupos de mujeres. Estos últimos incluyen distintos sectores: mujeres sindicalistas, mujeres en fábricas, mujeres evangélicas, mujeres de diversas etnias, mujeres en situación pública de prostitución, mujeres discapacitadas, escritoras, mujeres rurales y urbanas.

Otras prácticas educativas son los cursos metodológicos, tanto desde la universidad como desde ONGs, y la formación teológica en el Seminario Bautista y en la FEET.

\section{Consideraciones finales}

A manera de resumen, podemos reiterar que la Educación Popular Feminista surgió en América Latina debido a la ausencia palpable del tratamiento de las contradicciones de género en las diferentes experiencias de educación popular que desde la década de los sesenta impulsaron organizaciones populares, partidos de izquierda, movimientos eclesiales y proyectos de desarrollo.

En Nicaragua, después de una revolución inconclusa, las educadoras feministas siguen configurándose como sujetas cuya actuación o testimonio de denuncia y transformación radical pone de relieve los diversos aspectos injustos o deteriorados o inviables del sistema patriarcal y capitalista. Su testimonio de denuncia de este sistema las convierte en sujetas revolucionarias, hoy en día y desde siglos atrás. En la actualidad, siguen siendo las protagonistas del cambio social y las que demandaron que se diera una revolución dentro de la Revolución: una revolución feminista (Santamaría, 2002:112) y las que siguen abogando por el cambio social ahora en un contexto de involución.

El aporte más significativo de la Educación Popular Feminista ha sido incorporar al análisis de opresión propio de la EP la doble discriminación que sufren las mujeres de sectores populares, por razones de clase y género y un trabajo continuo por la eliminación de la dualidad clase-género, expresión de formas complementarias de dominación (Vinent, 2001). En ese sentido, la EPF apuesta a un proyecto que elimina toda subordinación: machismo, clasismo, racismo y, en definitiva, todo tipo de dominación (Rosero, 1987, en Vinent, 2001).

El reto de la EPF es profundizar en el abordaje de la esfera privada para educar de manera que permita superar las relaciones autoritarias, violentas y patriarcales que se dan dentro de las familias, escuela de los tipos de dominación que vivimos en la sociedad.

\section{Notas}

1. Expresión de Vidaluz Meneses, poeta cristiana feminista nicaragüense.

2. En todos estos tipos de organizaciones laboran las $67 \mathrm{EF}$ entrevistadas en la investigación para tesis doctoral que sirve de base a este artículo.

3. Para definiciones de educación, véase García y García, 1996, y Sarramona, 2000.

4. Sobre corrientes feministas, véase Aubert, Duque, Fisas y Valls, 2004; Molyneux, 2003; Nash, 2004; Puigvert, 2001; y Santamaría, 2002.

5. Definición elaborada con la colaboración de mi colega de doctorado Susan Francis y reelaborada con mi comunidad asesora en Nicaragua.

6. Documento Final del Concilio Vaticano II, 1965. 
7. Un modo de hacer teología que parte de la realidad de opresión latinoamericana y que inspira movimientos liberadores de iglesia. Dentro de ella, se incluye la teología feminista latinoamericana actual.

8. Así pues, la iglesia reconoce por primera vez a las mujeres pobres como sector "doblemente marginado y oprimido" en América Latina. III Conferencia Episcopal Latinoamericana en Puebla, México (1979), 1134-1140.

9. Este movimiento se ha desarrollado con más fuerza en Centroamérica y consiste en la formación teológico-pastoral básica para laicos -campesinos y pobladores pobres en su mayoría- de manera que, frente a la escasez de sacerdotes en las zonas marginales, ellos puedan encargarse de la celebración litúrgica dominical. Este movimiento plantea un modelo no clerical para la vida comunitaria de fe.

10. Edades al momento de las entrevistas (JulioSeptiembre 2004).

11. Todo este acápite son extractos de Levenberg, 1995, si bien con algunos datos actualizados.

\section{Referencias bibliográficas}

Araya, S. (2001). La equidad de género desde la representación social de las formadoras y los formadores del profesorado de segunda enseñanza. Disertación doctoral no publicada. Universidad de Costa Rica. Ciudad Universitaria Rodrigo Facio, Costa Rica.

Aubert, A.; Duque, E.; Fisas, M.; Valls, R. (2004.) Dialogar y transformar. Pedagogía crítica del siglo XXI. Col. Crítica y fundamentos, 2. Serie Teoría y sociología de la educación. Barcelona: Graó.

Bonder, G. (1994). "Mujer y Educación en América Latina: hacia la igualdad de oportunidades". Revista Iberoamericana de educación, 6, 9-48.

Cane, P. (2000). Trauma Healing and Transformation. Disertación doctoral no publicada. The Union Institute, Ohio, EEUU.

D’Angelo, A. (1999). Explorando nuestros cambios. Managua: Proyecto Mujer, Salud y Violencia - MUSAVIA.

De Souza, J. (2003). La educación agrícola superior latinoamericana ante la globalización. San José, Costa Rica: mimeo.

Fernández, M. (2002). Estado del arte y de la investigación de la educación de mujeres en América Latina desde una perspectiva feminista (19702002). Managua: mimeo.

Gallardo, H. (14 de julio de 2005). 44Segunda Época 1992. Noviembrediciembre. 1992. Disponible en: http://www.dei-cr.org/mostrar articulo_pasos.php?id=289\&pasos__ nro=44\&fecha_pasos=Segunda $\% 20$ Época\%201992:\%20Noviembre\%20$\% 20$ Diciembre\&especial=0

García, J.; (1996). García, A. Teoría de la educación I. Educación y acción pedagógica. Salamanca: Ediciones Universidad de Salamanca.

Gore, J. (1996). Controversias entre las pedagogías. Discursos críticos y feministas como regímenes de verdad. Madrid: Morata.

INEC/CELADE. (2003). Proyecciones y estimaciones de población, Nicaragua 1950-2050. En Agenda UNFPA Nicaragua 2004. Managua: UNFPA.

Kane, L. (2001). Popular Education and Social Change in Latin America. London, UK: Latin America Bureau.

Levenberg, R. (1995). "Educación y política en Centro América". En Puiggrós, Adriana; Lozano, Claudio (comp.). Historia de la Educación 
Iberoamericana Tomo I, p. 131-160. Buenos Aires: Miño y Dávila.

Messina, G. (2001). Estado del arte de la igualdad de género en la educación básica de América Latina (19902000). Santiago, Chile: UNESCO.

Molyneux, M. (2003/2001). Movimientos de mujeres en América Latina. Estudio teórico comparado. (Trad. Jaqueline Cruz. Título original: Women's Movements in International Perspective. Latin America and Beyond). Col. Feminismos, 76. Madrid: Cátedra.

Movimiento XXV Aniversario CNA. (2005). Proclama. Managua: mimeo.

Nadeau, D. (2002). s.n. Borrador de tesis doctoral. Vancouver, Canadá.

Nash, M. (2004). Mujeres en el mundo. Historia, retos y movimientos. Madrid: Alianza Editorial.

Núñez, C. (1989). Educar para transformar. Transformar para educar. San José, Costa Rica: ALFORJA. 5a. edición.

Pedersen, C.H. (1988). Nunca antes me habian enseñado eso. Capacitación feminista. Metodologí/comunicación/impacto. Lima: Lilith Ediciones.
Porta y Gutiérrez. (6Abril 2005). Radiografía del empirismo. (Censo Docentes 2002). Managua. 2003, Noviembre. En www.mecd.gob.ni

Puiggrós, A.; Lozano, C. (comp.). (1995). Historia de la Educación Iberoamericana Tomo I. Buenos Aires: Miño y Dávila.

Puigvert, Lídia. (2001). "Feminismo dialógico. Aportaciones de las "otras mujeres" a la transformación social de las relaciones de género". En Elisabeth Beck-Gernsheim, Judith Butler y Lidia Puigvert. Mujeres y transformaciones sociales. Col. Apertura. Barcelona: El Roure.

Santamaría, G. (2002). Alianza y autonomía: las estrategias políticas del movimiento de mujeres en Nicaragua. México, D.F.: mimeo.

Sarramona, Jaume. (2000). Teoría de la educación. Reflexión y normativa pedagógica. Barcelona: Ariel.

Toledo de Aguerri, J. (1940). Educación $y$ Feminismo. Sobre enseñanza. Artículos varios. Managua: Talleres Nacionales.

Vinent, I. (2001). Laeducación popular feminista y su aplicación en proyectos de capacitación jurídica y de desarrollo. Tesis doctoral presentada en la Universidad de Oviedo, Asturias, España. 
